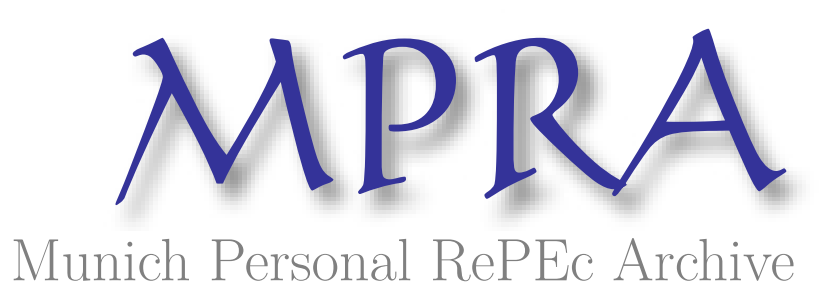

\title{
Aid and Public Sector Fiscal Behaviour in Failing States
}

Feeny, Simon and McGillivray, Mark

2009

Online at https://mpra.ub.uni-muenchen.de/21801/

MPRA Paper No. 21801, posted 03 Apr 2010 14:33 UTC 


\title{
Aid and Public Sector Fiscal Behaviour in Failing States
}

\author{
Simon Feeny ${ }^{a,{ }^{*}}$ and Mark McGillivray ${ }^{\mathrm{b}}$
}

${ }^{a}$ School of Economics, Finance and Marketing, RMIT University, Level 12, 239 Bourke Street, Melbourne, VIC 3000, Australia. Tel: +61 39925 5901, Fax: +61 39925 5986. Email: simon.feeny@rmit.edu.au

${ }^{\mathrm{b}}$ Alfred Deakin Research Institute, Deakin University, Melbourne, Australia.

${ }^{*}$ Corresponding author

Acknowledgements: This paper has been prepared within the UNU-WIDER project on Fragility and Development, which is directed by Mark McGillivray and Amelia Santos-Paulino. UNU-WIDER gratefully acknowledges the financial contribution to the project by the Australian Agency for International Development (AusAID). The first author is grateful for funding from the Australian Research Council and World Vision Australia. This paper benefited from fieldwork conducted in Papua New Guinea and Australia. The authors are grateful to numerous interviewees in Australia and Papua New Guinea, providing useful information, comments or background discussions. The views expressed in this publication are those of the authors. Publication does not imply endorsement by the Institute or the United Nations University, nor by the project sponsors, of any of the views expressed. 


\title{
Aid and Public Sector Fiscal Behaviour in Failing States
}

\begin{abstract}
This paper looks at interactions between foreign aid and the public sector in developing countries, especially those considered to be fragile or failing states. A model is proposed which employs actual budgetary appropriations and revenue estimates (rather than estimated target variables) and allows for asymmetric preference. Variants of the model are estimated using time-series data for Papua New Guinea (PNG). PNG is classified as a fragile state by the international community owing to perceived policy and institutional inadequacies. Results obtained suggest that foreign aid increases consumption and investment expenditures and decreases tax revenues and the level of borrowing.
\end{abstract}

JEL codes: $\mathrm{H}_{3}, \mathrm{H} 6, \mathrm{O}_{2}, \mathrm{C}_{5}$

Keywords: Foreign aid, taxes, public spending, fungibility, fragile states, failing states, Papua New Guinea. 


\section{Introduction}

The international community has acquired lofty expectations of foreign development aid in recent years, especially since the adoption of the Millennium Development Goals, (MDGs) at the United Nations (UN) Millennium Summit in September 200o. The MDGs aim inter alia to halve world-wide the number of people living in extreme income poverty world-wide by 2015 . Part of the strategy to achieve or at least work towards the MDGs is a substantial scaling up of aid flows by donor nations (UN Millennium Project Report, 2005). This is clearly evident in aid statistics, with global Official Development Assistance (ODA) rising from \$US69 billion in 2003 to around \$US106 billion in 2005. ODA is expected to rise to \$US130 billion in 2010 (OECD, 2006). While there is much optimism in the donor community about the impact of these flows, it has grave concerns about the effectiveness of aid to countries it classifies as 'fragile states'. The impact of aid on growth and poverty reduction and the ability to efficiently use additional inflows is thought to be substantially lower in these countries compared to other recipients. Donors rightly insist that unless aid can be made to work better in fragile or failing states the term preferred by and subsequently used in this paper), the intended developmental dividend from these increased flows will not be observed, and the world-wide achievement of the MDGs will not be possible in the foreseeable future, let alone by the agreed target of $2015 .{ }^{2}$ Collier (2007) argues that finding initiatives to help the bottom billion (about three quartes of which live in fragile or failing states) is one of the key challenges facing the world in the twenty-first century.

While the countries belonging to the donor community failing state group are diverse in many respects, they all share two common characteristics. The first is that they are desperately poor. According to one of the two classification criteria currently used by the donor community, 46 countries were classified as fragile (failing) states in $2004 \cdot{ }^{3}$ Roughly one-third of the world's population living in extreme income poverty resides in these states. This equates to 340 million people. Of the estimated 10.8 million children that died before their fifth birthday in 2002, just over 40 percent lived in these 46 states (Branchflower et al. 2004). The second characteristic is that they all have critically substandard public policies, poorly performing public institutions, or both. Donors actually use a measure of policy quality and institutional performance - the World Bank's Country Policy and Institutional Assessment (CPIA) - to deem a country fragile. It is indeed on the basis of this specific characteristic that donors primarily believe that these countries use aid poorly. ${ }^{4}$

Concerns over the likely impact of aid to failing states are broadly consistent with points long recognised in the research literature: recipient country public sectors are key players in determining the effectiveness of aid and that the broader impacts of these inflows are mediated by the manner in whichpublic sectors use aid inflows. ${ }^{5}$ The second of these points has been addressed in a research literature that dates back to the 1970s that looks at the impact of aid on various categories of public sector revenue and expenditure. This research has its origins in the seminal work of Heller (1975), which went largely unnoticed in the literature on aid for a 
number of years. Gang and Khan (1991), in an important study, changed this state of affairs by applying Heller's model to time series data for India. ${ }^{6}$ Chishti and Hasan (1992), Khan and Hoshino (1992), Binh and McGillivray (1993), Gang and Khan (1993, 1999), Khan (1994), McGillivray (1994), White (1994), Otim (1996), Franco-Rodriguez et al. (1998), McGillivray and Ahmed (1999), Franco-Rodriguez (2000), McGillivray (2000), Mavrotas (2002, 2005), McGillivray and Ouattara (2005), Mavrotas and Ouattara (2006,) Ouattara (2006a, 2006b) and Feeny (2006, 2007) have all followed Gang and Khan's lead with their own contributions to the 'fiscal response' literature, a term attributed to White (1992). ${ }^{7}$

The fiscal response literature has advanced both conceptually and econometrically as a result of the preceding studies. Advances include more theoretically sound and institutionally realistic utility function and constraint equation specifications, basing conclusions and policy recommendations on both reduced-form and structural equation parameter estimates, endogenising aid, analysing alternative aid disaggregations, using time-series data and the reporting of constraint and structural equation parameters consistent with the underlying theory. While these advances are important, it is widely acknowledged that there is still plenty of room for further improvement in both the design and application of fiscal response models (McGillivray and Morrissey, 2001a). In particular, no study has been able to address satisfactorily the two deficiencies widely thought to be the most serious in the fiscal response literature: the reliance on crudely estimated revenue and expenditure targets and the use of a utility function premised on perfectly symmetric policymaker preferences. ${ }^{8}$ Failing states have also been very much under-represented in the fiscal response literature, although this is understandable given that conditions in these countries are such that their failings include the reporting of requisite data. Only two of the above-cited studies, McGillivray and Ouattara (2005) and Mavrotas and Ouattara (2006), have looked specifically at a country classified as failing state. Both, however, looked at the case of Cotê d'Iviore. ${ }^{9}$ More knowledge of the fiscal response to aid inflows in these countries is crucial, arguably more so than in other aid recipients.

This paper addresses both of the just-mentioned deficiencies. It builds on the work of Gang and Khan (1999) through its consideration of asymmetric preferences. It develops a generic fiscal response model that allows for asymmetric preferences and estimates this model using actual expenditure appropriations and revenue estimates instead of target estimates. It reveals that the problem with using estimated target values is far more serious than previously understood in the literature, and has in all likelihood led to seriously misleading policy recommendations. A specific form of this model is applied to Papua New Guinean time-series data for the period 1969 to 2000. This model has been largely based on fieldwork conducted in Papua New Guinea. Estimates of structural and reduced form parameters are provided, based on alternative disaggregations of aid inflows.

While the modelling approach of this paper has a general appeal to the analysis of aid impact, a focus on Papua New Guinea (PNG) is interesting in its own right, for three reasons. 
First, PNG is unlike most other failing states in that the country has published annual data since the early 1960 s on various categories of planned and actual revenues and expenditures. These data permit the estimation of a suitably specified fiscal response model. This in turn provides the potential for insights into the relationship between aid and various fiscal aggregates that are simply not possible for most failing states, and many other developing nations as well. Second, the level of official aid to PNG is particularly large. It has averaged 35 percent of government revenue since 1960, reaching as much as 60 percent in some years, and is much greater in magnitude than private foreign inflows (GPNG, 1962-2002, OECD, 2005). No other South Pacific country has received as much aid since 1960 as PNG (OECD, 2005). In per capita terms, aid to PNG has averaged US\$90 since 1975 - nine times the average per capita receipts of all developing countries over the last ten years (OECD, 2005, UNDP, 1993-2003). Not only does this level of aid suggest that it is likely to have had observable impacts, but that the outlay of donor taxpayer funds warrants an evaluation of these impacts.

Second, PNG has experienced increasingly difficult times in recent decades (Windybank and Manning, 2003). PNG in many respects resembles the stereotypical failing, although still functioning, developing country. Achieving independence in the mid-1970s, PNG has experienced or exhibited frequent changes of government, a civil war, a military that has threatened revolt on a number of occasions, seemingly endemic corruption, a rapidly growing HIV/AIDS problem, low levels of personal security and a very poorly performing economy according to most if not all criteria. Some studies assert that foreign aid has actually contributed to aspects of PNG's decline (Hughes, 2003, Windybank and Manning, 2003). While there is little scientific evidence to support this claim, it is widely recognised that the PNG public sector has limited capacities to perform a number of functions, including the efficient application of aid inflows. This is reflected in it being classified by the international donor community as a fragile state, based on it being rated in the bottom two quintiles of CPIA scores (World Bank, 2003, Jones et al., 2004, McGillivray, 2005). In a further, somewhat radical and controversial response to the deteriorating position in the South Pacific's largest country, Australia, the lead PNG donor, has recently placed its own civil servants in various PNG government departments to help strengthen the level of economic and public sector management (AusAID, 2004). The case for a formal evaluation of the impact of aid on public sector fiscal aggregates in PNG appears stronger, given this background. Moreover, as a seemingly typical failing state, knowledge of the fiscal impact of aid to PNG might provide useful insights into aid effectiveness in other such states.

This paper is structured as follows. Section II develops a general fiscal response model that both builds on past developments in, and addresses remaining inadequacies of, the fiscal response literature. Included in Section II is a discussion of the relevance of this model to failing states. Section III outlines various versions of the fiscal response model that will subsequently be estimated using PNG data. Section IV discusses data and estimation issues, prior to reporting results from estimating these versions of the model for PNG. Section IV also draws inferences 
from these results for the broader impacts of aid to PNG, as well as comparing them with results from fiscal studies of other recipient countries, seeking to ascertain how PNG rates in a broader international context. Section V concludes, identifying implications for policy, both in PNG and other failing states.

\section{Modelling Fiscal Response}

Fiscal response models envisage maximising the utility of public sector fiscal decision makers. These decision makers possess well-behaved, homothetic preference maps and behave as if they were a single individual. They strive to achieve exogenously-determined annual targets for the actual (endogenous) revenue and expenditure aggregates, subject to budget constraints. While a number of different utility function specifications have been employed in the literature, almost all fiscal response studies since Binh and McGillivray (1993) employ a quadratic loss function of the following general form:

$$
U=\alpha-\sum_{j=1}^{k} \frac{\beta_{j}}{2}\left(E_{j}-E_{j}^{*}\right)^{2}-\sum_{m=1}^{n} \frac{\gamma_{m}}{2}\left(R_{m}-R_{m}^{*}\right)^{2}
$$

where $E_{j}$ are actual expenditure aggregates, $R_{m}$ are actual revenue aggregates, $E_{\mathrm{j}}^{*}$ and $R_{j}^{*}$ are corresponding targets, $\alpha$ is a constant and $\beta$ and $\gamma$ are parameters. The expenditure variables are usually divided into capital (fixed investment) and recurrent (consumption) expenditures. Borrowing, to finance an excess of recurrent expenditures over recurrent revenues, is included in the revenue variables. It is common to also include aid variables among both the actual and target variables, subsequent to Franco-Rodriguez et al. (1998). It is apparent from (1) that the maximum unconstrained level of decision maker utility is $\alpha$, which is reached if all targets are exactly achieved. Moreover, as Binh and McGillivray (1993) point out, (1) is perfectly symmetric, in that overshooting a target by a given amount will result in the same loss of utility as undershooting by that amount.

A number of different constraints have been proposed since the original study of Heller (1975). Most recent studies have followed Franco-Rodriguez et al. (1998) by maximising a specific form of (1) subject to variants of the following constraint equations:

$$
\begin{aligned}
& \sum_{j=1}^{k} E_{j}=\sum_{m=1}^{n} R_{m} \quad \text { and } \\
& \sum_{j=q+1}^{k} E_{j} \leq \sum_{m=1}^{n} \rho_{m} R_{m}
\end{aligned}
$$

where $q$ refers to the public investment aggregates included among $E_{j}(j=1, \ldots, q, \ldots, k)$ and $\rho_{m}$ are the proportions of each revenue aggregate allocated to consumption expenditures. Equation (2) is simply the government's overall budget constraint that must always hold. Equation (3) refers to the recurrent budget, and it follows from this equation that $1-\rho_{m}$ are the proportions of each revenue variable allocated to investment expenditures. 
The rationale for the inequality written in (3) is that there are pressures that limit the manner in which the public sector in developing countries allocates revenues. The actions of donors or domestic interests cause the values of the $\rho s$ in (3) to be imposed on those involved in setting expenditures and allocating revenue, with there being no guarantee that expenditures can be met even though revenues may satisfy (2). Put differently, on the assumption that (3) is binding, with the possible values of the chosen recurrent expenditure variables being upper bound, these external constraints prevent the attainment of $\alpha$ because at least one expenditure appropriation cannot be met. If (3) is not binding the government is not prevented from reaching specific expenditure targets, utility is maximised subject to (2) only and the government can attain $\alpha$ if revenues are sufficient (Franco-Rodriguez et al., 1998). ${ }^{10}$ In what follows we assume (3) to be binding, like all studies subsequent to Franco-Rodriguez et al..

The general form of the Franco-Rodriguez et al. (1998) constraints, as depicted by (2) and (3), would appear to be valid. Subsequent studies seem to agree as these constraints are now commonplace in the fiscal response literature. The utility function written in (1) is problematic, however, in two respects. The first concerns its symmetry. As mentioned, this is one perceived weakness that much of the fiscal response literature has not satisfactorily addressed. While it is reasonable to posit that exactly meeting all targets is optimal for public sector decision makers, it would appear to be unrealistic to expect that undershooting is equally as bad as overshooting for all fiscal aggregates. One possibility is that undershooting an expenditure target results in a greater utility loss than overshooting it, with the reverse being the case with revenue targets. Gang and Khan (1999) found empirical support for these outcomes in the case of India. This outcome was built into the linear quadratic utility function adopted by some studies (Heller, 1975, Gang and Khan, 1991, Khan and Hoshino, 1992, and Otim, 1996). ${ }^{11}$ Binh and McGillivray (1993) demonstrate, however, that such a specification is not theoretically viable, as it is not well-behaved in the conventional sense, and does not reach a maximum when all of the variables are equal to their targets. ${ }^{12}$ What would appear to be required is a utility function that not only satisfies these attributes but also allows for other feasible asymmetries. It might not be the case, for example, that undershooting all revenue variables is preferred. Preferences will ultimately depend on the particular circumstances of the fiscal decision makers under consideration, and researchers will need some knowledge to justify how the utility function should be specified. Feeny (2006) offers a solution to this problem, by proposing a utility function that satisfies both of the above attributes and incorporates a range of feasible asymmetric preferences. We outline this function below.

The second problem relates to the target variables, $E_{j}^{*}$ and $R_{j}^{*}$. Despite the centrality of the targets in fiscal response models, the literature has been blind as to how these variables might be formulated. There is an absence of any story of how targets are determined, be it in the form of a formal theoretical framework or simple intuitive reasoning. Nor is any support given for the assumption that they are exogenous. It could be the case, for example, that decision makers adjust targets contemporaneously according to actual revenues and expenditures. For 
example, a tax revenue target might be adjusted downwards if it appears that actual tax revenues are likely to fall well short of the target. Treating the tax target as exogenous would seem dubious, should such adjustments occur.

Most seriously, none of the studies cited above have used actual target variables, due to difficulties in obtaining data on them. This is perhaps not surprising given the ambiguous status of these variables. Estimated target variable values have been used, therefore, to estimate the structural and reduced form equations derived from maximising (1) subject to (2) and (3). ${ }^{13}$ These estimates are obtained by firstly estimating:

$$
\begin{aligned}
& E_{j}=\theta_{j}+\sum_{w=1}^{v} \Phi_{w, j} Y_{w, j}+\varepsilon_{j} \quad \text { and } \\
& R_{m}=\theta_{m}+\sum_{w=1}^{v} \Phi_{w, m} Z_{w, m}+\varepsilon_{m}
\end{aligned}
$$

where $\theta_{j}$ and $\theta_{m}, \Phi_{w, j}$ and $\Phi_{w, m}, Y_{w, j}$ and $Z_{w, m}$ and $\varepsilon_{j}$ and $\varepsilon_{m}$ are constants, vectors of parameters, vectors of variables and error terms, respectively, and $v$ is a number typically three or more. The fitted value of $E_{j}$ and $R_{m}$ are then treated as estimates of $E_{j}^{*}$ and $R_{m}^{*}{ }^{*}{ }^{14}$ This procedure invokes the well-documented problem of using generated regressors in an empirical model (see, for example, Pagan, 1984 and Woodridge, 2002). Unless the target variables are asymptotically orthogonal to the error terms of the structural equations, the resulting standard errors will be inefficient and $t$-statistics invalid (see Wooldridge, 2002, pp.115-16). The fiscal response literature has been blind to this issue.

But the problem of obtaining targets in the way described is far worse than that associated with the use of generated regressors, for reasons so far largely overlooked in the fiscal response literature. Each structural equation contains the target corresponding to its dependent variable (the investment equation contains the investment target as an explanatory variable, the taxation revenue equation contains the tax target as an explanatory variable and so on). Given that the fitted value of any given variable is simply its actual value minus a residual, substituting the targets, as defined, into the structural equations and then estimating these equations involves a regression of each dependent variable on itself. As a consequence the resulting estimates will be biased and inconsistent and therefore misleading. Moreover, since the reduced form equation estimates in most fiscal response studies have been obtained from the estimated structural parameters, the former are also likely to be misleading. This is a serious issue, given the many policy recommendations that have been provided on the basis of these results. The literature has been blind to this point, tending simply to label the estimates as crude or rough approximations and not considering the implications of how they are obtained. ${ }^{15} \mathrm{Given}$ this problem and the others outlined above, an alternative to the use of these targets is clearly warranted.

A brief examination of actual budgetary processes, common world-wide, points to a 
potential alternative. Public sectors work in any given year to budgetary expenditure appropriations and corresponding revenue estimates. These estimates for developing countries will include anticipated aid inflows, which will be based on agreements reached with donor countries and multilateral agencies. Typically approved by parliament or a delegated authority, the appropriations permit public sector agencies to incur obligations and to make payments from the revenues at their disposal. Annual expenditure appropriations and revenue estimates are usually formulated and published in the year prior to that to which they apply (that is, they are formulated for period $t$ in period $t-1) .{ }^{16}$ As such they are predetermined, or exogenous, with respect to actual revenues and expenditures. Appropriations or revenue estimates might of course be changed in the current period, as occurs with supplemental appropriations. Expenditure appropriations might be reduced, for instance, if projected revenues have been over-estimated or vice versa. Alternatively, these appropriations might be increased, say in response to some emergency, and estimated revenue (most probably borrowing) revised upward. In each case this implies that at least one category of expenditure appropriation or revenue estimate would be endogenous with respect to the corresponding actual variable. But any such scenario is almost sub-optimal from the perspective of the public sector, involving many difficulties and increased uncertainty. The optimal scenario is to bring the budget in according to the predetermined appropriations or revenue estimates.

It could well be the case that these appropriations and estimates are the targets alluded to in the fiscal response literature. However, there is a subtle but important distinction, which has implications for how one conceptualises public sector behaviour. Consider a public sector that contains reasonably independent, less than passive, or even maverick decision makers. It might ignore, to varying degrees, expenditure aggregates and revenue estimates and instead work to independently formulated targets. Expenditure targets and appropriations will differ in this case, therefore, as will revenue targets and estimates. Alternatively, a more dependent public sector might passively accept the appropriations and revenue estimates, accepting them as its targets and ensuring that its behaviour is in concordance with them. Decision makers within these agencies will be concerned about getting a 'slap on the wrist' or some other form of more serious retaliatory behaviour from their political masters or more influential areas of the public sector for overspending or not generating sufficient revenue. In the current paper we assume the latter scenario only, believing it to be appropriate to the public sector in most developing countries, including PNG, the country examined later in this paper. ${ }^{17}$

Following Feeny $(2006,2007)$ and building on the preceding comments we posit the following public sector decision maker utility function:

$$
U=\alpha-\sum_{j=1}^{k}\left(e\left[\beta_{j}\left(E_{j}^{\#}-E_{j}\right)\right]-\beta_{j}\left(E_{j}^{\#}-E_{j}\right)-1\right)-\sum_{m=1}^{n}\left(e\left[\gamma_{j}\left(R_{m}-R_{m}^{\#}\right)\right]-\gamma_{j}\left(R_{m}-R_{m}^{\#}\right)-1\right)
$$

where $E_{j}^{*}$ and $R_{j}^{*}$ denote expenditure appropriations and revenue estimates, respectively. Equation (4) reaches a maximum at $\alpha$, which is achieved if all appropriations and estimates are 
achieved, and is well-behaved in that it ensures diminishing marginal utility at all levels of $E_{j}$ and $R_{m} \cdot{ }^{18}$

Forming a Lagrangean from (2), (3) and (4) and partially differentiating it yields the following first-order conditions:

$$
\begin{array}{ll}
\frac{\partial L}{\partial E_{j}}=\beta_{j} e\left[\beta_{j}\left(E_{j}^{\#}-E_{j}\right)\right]-\beta_{j}+\lambda_{1}=0 & \text { for } j=1, \ldots, q, \\
\frac{\partial L}{\partial E_{j}}=\beta_{j} e\left[\beta_{j}\left(E_{j}^{\#}-E_{j}\right)\right]-\beta_{j}+\lambda_{1}+\lambda_{2}=0 & \text { for } j=q+1, \ldots, k, \\
\frac{\partial L}{\partial R_{m}}=-\gamma_{m} e\left[\gamma_{m}\left(R_{m}-R_{m}^{\#}\right)\right]+\gamma_{m}-\lambda_{1}-\lambda_{2} \rho_{m}=0 & \text { for } m=1, \ldots, n, \\
\frac{\partial L}{\partial \lambda_{1}}=\sum_{j=1}^{k} E_{j}-\sum_{m=1}^{n} R_{m}=0 \text { and } & \\
\frac{\partial L}{\partial \lambda_{2}}=\sum_{j=q+1}^{k} E_{j}-\sum_{m=1}^{n} \rho_{m} R_{m}=0 . &
\end{array}
$$

Due to the exponential terms it is not possible to rearrange the first order conditions algebraically to obtain structural equations suitable for estimation. However, using Taylor's approximation, in which $e^{x} \approx 1+x$, the first order conditions can be rewritten as: ${ }^{19}$

$$
\begin{array}{ll}
\frac{\partial L}{\partial E_{j}}=\beta_{j}^{2}\left(E_{j}^{\#}-E_{j}\right)+\lambda_{1}=0 & \text { for } j=1, \ldots, q, \\
\frac{\partial L}{\partial E_{j}}=\beta_{j}^{2}\left(E_{j}^{\#}-E_{j}\right)+\lambda_{2}=0 & \text { for } j=q+1, \ldots, k, \\
\frac{\partial L}{\partial R_{m}}=-\gamma_{m}^{2}\left(R_{m}-R_{m}^{\#}\right)-\lambda_{1}\left(1-\rho_{m}\right)-\lambda_{2} \rho_{m}=0 & \text { for } m=1, \ldots, n, \\
\frac{\partial L}{\partial \lambda_{1}}=\sum_{j=1}^{k} E_{j}-\sum_{m=1}^{n} R_{m}=0 \text { and } & \\
\frac{\partial L}{\partial \lambda_{2}}=\sum_{j=q+1}^{k} E_{j}-\sum_{m=1}^{n} \rho_{m} R_{m}=0 . &
\end{array}
$$

Fiscal response models have varied in terms of the number of expenditure and revenue variables. In rearranging the first order conditions written in (5) to (9), it is assumed that there is one investment and two consumption expenditure variables ( $E_{1}, E_{2}$ and $E_{3}$, respectively), one taxation variable $\left(R_{1}\right)$, two aid variables $\left(R_{2}\right.$ and $R_{3}$, respectively) and a single (non-aid) borrowing variable $\left(R_{4}\right)$. This is consistent with the application outlined in the remaining sections and with a number of previous fiscal response studies. Rearranging (5) to (9) with these variables yields the following structural equations: 


$$
\begin{aligned}
E_{1}= & \Phi_{1}\left(1-\rho_{1}\right) E_{1}^{\#}+\left(1-\rho_{1}\right)\left(\Phi_{1}+\phi_{2}\right) E_{2}^{\#}+\left(1-\rho_{1}\right)\left(\Phi_{1}+\beta_{2}\right) E_{3} \\
+ & {\left[\left(1-\rho_{1}\right)\left(1-\rho_{1} \Phi_{2}-\Phi_{2}\right)\right] R_{1}^{\#}+\left[\left(1-\rho_{2}\right)-\left(1-\rho_{1}\right)\left(\rho_{2} \Phi_{2}+\Phi_{1}\right)\right] R_{2} } \\
& +\left[\left(1-\rho_{3}\right)-\left(1-\rho_{1}\right)\left(\rho_{3} \Phi_{2}+\Phi_{1}\right)\right] R_{3}+\left[\left(1-\rho_{3}\right)-\left(1-\rho_{1}\right)\left(\rho_{4} \Phi_{2}+\Phi_{1}\right)\right] R_{4}, \\
E_{1}= & \rho_{1} \Phi_{1} E_{1}^{\#}+\rho_{1}\left(\Phi_{1}+\Phi_{2}\right) E_{2}^{\#}-\left(1-\rho_{1} \Phi_{2}-\rho_{1} \Phi_{1}\right) E_{3} \\
& +\rho_{1}\left(1-\rho_{1} \Phi_{2}-\Phi_{1}\right) R_{1}^{\#}+\left[\rho_{2}-\rho_{1}\left(\Phi_{1}+\rho_{2} \Phi_{2}\right)\right] R_{2}+\left[\rho_{2}-\rho_{1}\left(\Phi_{1}+\rho_{3} \Phi_{2}\right)\right] R_{3} \\
& +\left[\rho_{4}-\rho_{1}\left(\Phi_{1}+\rho_{4} \Phi_{2}\right)\right] R_{4} \\
E_{3}= & \rho_{1} \Phi_{3} E_{1}^{\#}-\left(1-\rho_{1} \Phi_{4}-\rho_{1} \Phi_{3}\right) E_{2}+\left[\left(1-\left[\left(1-\rho_{1}\right) \Phi_{3}\right]\right)-\left(1-\rho_{1} \Phi_{4}-\Phi_{3}\right)\right] E_{3}^{\#} \\
& +\rho_{1}\left(1-\rho_{1} \Phi_{4}-\Phi_{3}\right) R_{1}^{\#}+\left[\rho_{2}-\left(\rho_{1} \Phi_{3}+\rho_{1} \rho_{2} \Phi_{4}\right)\right] R_{3}+\left[\rho_{3}-\left(\rho_{1} \Phi_{3}+\rho_{1} \rho_{3} \Phi_{4}\right)\right] R_{3} \\
& +\left[\rho_{4}-\left(\rho_{1} \Phi_{3}+\rho_{1} \rho_{4} \Phi_{4}\right)\right] R_{4}, \\
R_{1}= & \Phi_{1} E_{1}^{\#}+\left(\Phi_{1}+\Phi_{2}\right) E_{2}^{\#}+\left(\Phi_{1}+\Phi_{2}\right) E_{3}+\left(1-\rho_{1} \Phi_{2}-\phi_{2}\right) R_{1}^{\#}-\left(\rho_{2} \Phi_{2}+\Phi_{1}\right) R_{2} \\
& -\left(\rho_{3} \Phi_{3}+\Phi_{1}\right) R_{3}-\left(\rho_{4} \Phi_{2}+\Phi_{2}\right) R_{4}, \\
R_{2}= & \Phi_{5} E_{1}^{\#}+\left(\Phi_{5}+\phi_{6}\right) E_{2}^{\#}+\left(\Phi_{5}+\Phi_{6}\right) E_{3}+\left(1-\rho_{3} \Phi_{6}-\Phi_{5}\right) R_{2}^{\#} \\
& -\left(\rho_{3} \Phi_{2}+\mathrm{K}_{1}\right) R_{3}-\left(\rho_{1} \Phi_{6}+\Phi_{5}\right) R_{1}-\left(\rho_{4} \Phi_{6}+\Phi_{5}\right) R_{4}, \\
R_{3}= & \Phi_{7} E_{1}^{\#}+\left(\Phi_{7}+\Phi_{8}\right) E_{2}^{\#}+\left(\Phi_{7}+\Phi_{8}\right) E_{3}-\left(\rho_{1} \Phi_{8}+\beta_{7}\right) R_{1}-\left(\rho_{2} \Phi_{8}+\Phi_{7}\right) R_{2} \\
& +\left(1-\rho_{3} \Phi_{8}-\beta_{7}\right) R_{3}^{\#}-\left(\rho_{4} \Phi_{8}+\Phi_{7}\right) R_{4} \\
R_{4}= & \Phi_{9} E_{1}^{\#}+\left(\Phi_{9}+\Phi_{10}\right) E_{2}^{\#}+\left(\Phi_{9}+\Phi_{10}\right) E_{3}-\left(\rho_{1} \Phi_{10}+\Phi_{9}\right) R_{1}-\left(\rho_{2} \Phi_{10}+\Phi_{9}\right) R_{2} \\
& -\left(\rho_{3} \Phi_{10}+\Phi_{9}\right) R_{3}+\left(1-\rho_{4} \Phi_{10}-\Phi_{9}\right) R_{4}^{\#}
\end{aligned}
$$

where

$$
\begin{aligned}
& \Phi_{1}=\frac{\beta_{3}^{2}\left(1-\rho_{1}\right)}{\theta_{1}}, \Phi_{2}=\frac{\beta_{1}^{2} \rho_{1}-\beta_{3}^{2}\left(1-\rho_{1}\right)}{\theta_{1}}, \Phi_{3}=\frac{\beta_{3}^{2}\left(1-\rho_{1}\right)}{\theta_{2}}, \Phi_{4}=\frac{\beta_{2}^{2} \rho_{1}-\beta_{3}^{2}\left(1-\rho_{1}\right)}{\theta_{2}} \\
& \Phi_{5}=\frac{\beta_{3}^{2}\left(1-\rho_{2}\right)}{\theta_{3}}, \Phi_{6}=\frac{\beta_{1}^{2} \rho_{2}-\beta_{3}^{2}\left(1-\rho_{2}\right)}{\theta_{3}}, \Phi_{7}=\frac{\beta_{3}^{2}\left(1-\rho_{3}\right)}{\theta_{4}}, \Phi_{8}=\frac{\beta_{1}^{2} \rho_{3}-\beta_{3}^{2}\left(1-\rho_{3}\right)}{\theta_{4}} \\
& \Phi_{9}=\frac{\beta_{3}^{2}\left(1-\rho_{4}\right)}{\theta_{5}}, \Phi_{10}=\frac{\beta_{1}^{2} \rho_{4}-\beta_{3}^{2}\left(1-\rho_{4}\right)}{\theta_{5}}
\end{aligned}
$$

and

$$
\begin{aligned}
& \theta_{1}=\gamma_{1}^{2}+\beta_{1}^{2} \rho_{1}^{2}+\beta_{3}^{2}\left(1-\rho_{1}\right)^{2}, \theta_{2}=\gamma_{1}^{2}+\beta_{2}^{2} \rho_{1}^{2}+\beta_{3}^{2}\left(1-\rho_{1}\right)^{2}, \\
& \theta_{3}=\gamma_{2}^{2}+\beta_{2}^{2} \rho_{1}^{2}+\beta_{3}^{2}\left(1-\rho_{2}\right)^{2}, \theta_{4}=\gamma_{3}^{2}+\beta_{1}^{2} \rho_{3}^{2}+\beta_{3}^{2}\left(1-\rho_{3}\right)^{2} \quad \text { and } \\
& \theta_{5}=\gamma_{4}^{2}+\beta_{1}^{2} \rho_{4}^{2}+\beta_{3}^{2}\left(1-\rho_{4}\right)^{2} .
\end{aligned}
$$

Simultaneously solving (10) to (16) yields the following reduced form equations: 


$$
\begin{aligned}
& E_{1}=\pi_{1} E_{1}^{\#}+\pi_{2} E_{2}^{\#}+\pi_{3} E_{3}^{\#}+\pi_{4} R_{1}^{\#}+\pi_{5} R_{2}^{\#}+\pi_{6} R_{3}^{\#}++\pi_{7} R_{4}^{\#}, \\
& E_{2}=\pi_{8} E_{1}^{\#}+\pi_{9} E_{2}^{\#}+\pi_{10} E_{3}^{\#}+\pi_{11} R_{1}^{\#}+\pi_{12} R_{2}^{\#}+\pi_{13} R_{3}^{\#}++\pi_{14} R_{4}^{\#}, \\
& E_{3}=\pi_{15} E_{1}^{\#}+\pi_{16} E_{2}^{\#}+\pi_{17} E_{3}^{\#}+\pi_{18} R_{1}^{\#}+\pi_{19} R_{2}^{\#}+\pi_{20} R_{3}^{\#}++\pi_{21} R_{4}^{\#}, \\
& R_{1}=\pi_{22} E_{1}^{\#}+\pi_{23} E_{2}^{\#}+\pi_{24} E_{3}^{\#}+\pi_{25} R_{1}^{\#}+\pi_{26} R_{2}^{\#}+\pi_{27} R_{3}^{\#}++\pi_{28} R_{4}^{\#}, \\
& R_{2}=\pi_{29} E_{1}^{\#}+\pi_{30} E_{2}^{\#}+\pi_{31} E_{3}^{\#}+\pi_{32} R_{1}^{\#}+\pi_{33} R_{2}^{\#}+\pi_{34} R_{3}^{\#}++\pi_{35} R_{4}^{\#}, \\
& R_{3}=\pi_{36} E_{1}^{\#}+\pi_{37} E_{2}^{\#}+\pi_{38} E_{3}^{\#}+\pi_{39} R_{1}^{\#}+\pi_{40} R_{2}^{\#}+\pi_{41} R_{3}^{\#}++\pi_{42} R_{4}^{\#} \text { and } \\
& R_{4}=\pi_{43} E_{1}^{\#}+\pi_{44} E_{2}^{\#}+\pi_{45} E_{3}^{\#}+\pi_{46} R_{1}^{\#}+\pi_{47} R_{2}^{\#}+\pi_{48} R_{3}^{\#}++\pi_{49} R_{4}^{\#}
\end{aligned}
$$

where $\pi$ s are complex combinations of the $\Phi$ and $\rho$ parameters. ${ }^{20}$

Is it appropriate at this point to ask whether the model just outlined is suitable for analysing the fiscal impact of aid in failing states. The answer to this question would appear $a$ priori to be yes, with the exception of extreme cases in which the state in question has no functioning public sector, to the extent that it is very typically the case that these sectors work to expenditure appropriations and revenue estimates. The model is also static, like its predecessors. While this might well be a valid criticism of fiscal response models applied to nonfailing states, anecdotal evidence suggests that public sector fiscal behaviour tends not to be dynamic. Based on field interviews, this certainly seems to be true for PNG. The case for the above answer is stronger owing to the model being able to accommodate different fiscal decision maker preferences, unlike it predecessors. The presentation of the model above is premised on the assumption, stated above, that undershooting being preferred to overshooting for all expenditure appropriations, and the reverse for revenue estimates. If one was to assume alternatively that for any given expenditure variable undershooting is preferred to overshooting, (4) is rearranged by simply reversing the order in which the actual and appropriation variables appear, subtracting the latter from the former. Likewise, (4) can be adjusted for a situation in which revenue estimate overshooting is preferred simply by subtracting the actual variable from the estimate. It is posited that overshooting all variables, relative to undershooting, is the most likely preference in failing states. This is consistent with the general view of fiscal behaviour in such states, and is often a factor contributing to their classification by the donor community as fragile.

Two further aspects of the model would appear to be appropriate for analysing aid to failing states. First, it is well-known that there are especially strong pressures that limit the manner in which public sectors in failing states allocate revenues, particularly from domestic groups. The inequality constraint written in (3) thus would appear most applicable to these states. Second, it is also reasonably well-known that failing states are not adverse to borrowing, be it in the form of aid loans or other sources of finance. Previous fiscal response studies have in general assumed ex ante that exogenous non-aid borrowing (the borrowing target, $B^{*}$ ) is zero. As such they have in effect assumed that any borrowing results from anticipated revenue 
shortfalls. This would appear to be a dubious assumption to apply to failing states as they tend to plan to borrow from various sources in the cover expenditure appropriations. The borrowing estimate $\left(R_{4}^{*}\right)$, the equivalent of the borrowing target in previous fiscal response models, is therefore non-zero in equation (16) above.

\section{Modelling Aid and Public Sector Behaviour in PNG}

Let us now consider specific applicability of the model to PNG. The public sector in PNG does work with expenditure appropriations and revenue estimates that are approved by parliament at the start of each fiscal year. Public sector officials directly involved in fiscal decision making in PNG work to achieve these aggregates, although they do not lose as much utility from overshooting them than when they undershoot them. This seems to apply to all broad revenue and expenditure categories, including borrowing. Despite there being systems in place to restrict appropriation overruns, they are rarely enforced in PNG. While officials are well aware that overshooting revenue estimates has political costs and in the case of aid inflows does incur the wrath of donors, they view undershooting these estimates as especially undesirable and treat overshooting as a clearly better outcome on balance. The remaining analysis is premised, therefore, on the assumption that overshooting is preferred to undershooting for all endogenous variables in our fiscal response model.

PNG officials are also under intense external pressure in the allocation of revenues among expenditure categories. It is well known, for instance, that PNG politicians take active steps to ensure that revenues are allocated towards the needs of their own constituents as a means of increasing or maintaining public support. It is also well known that bureaucrats without direct responsibility for fiscal decision making attempt to influence these decisions to favour their home provinces. Moreover, donors attempt to restrict the amount of aid devoted to non-investment expenditures while informed sections of the electorate will also want to restrict the amount of borrowing and tax revenue devoted to these expenditures.

It was noted above that fiscal behaviour in PNG has tended not be forward looking, both in recent years and historically. Interviews with those involved directly in or observing this behaviour thought that its static nature largely reflects general behavioural tendencies in PNG, made stronger by uncertainty over future conditions. This reflects the reality that governments, policies, economic conditions and public sector personal can change frequently over time. A further reality of PNG budgetary behaviour is that successive governments have planned to borrow in order to cover expenditure appropriations. This is clear from an examination of PNG's budget papers (GPNG, 1962-2002).

Having argued for the applicability of the model outlined above to PNG, we now turn to the specific forms of it that are appropriate to analysing fiscal response in this country. Our starting point is information provided in official PNG budgetary data. PNG Budget Papers: Estimates of Revenue and Expenditure (GPNG, 1962-2000) provides information that allows public expenditure to be divided threefold, into fixed public investment, recurrent expenditure or consumption on items with a human capital orientation, and other recurrent expenditure. 
This is the traditional expenditure disaggregation used in the fiscal response literature and there would appear to be no compelling grounds to depart from it in the case of PNG. Revenue is broken down into taxation and other recurrent revenue, aid and borrowing from domestic and international sources not classified as aid. The Budget Papers report information on six overlapping categories of aid inflows: aid grants; aid loans; total aid from its principal donor, Australia; aid from other international donors; aid provided in the form of budget support, and; project aid (GPNG, 1962-2002). Total aid is obtained by either summing grants and loans, Australian and other aid or budget support and project aid. Importantly, appropriation or estimate information is available for all of these variables.

There can only be one true model of aid and public sector fiscal behaviour in PNG and ideally one would have good a priori information as to the correct aid disaggregation. Ideally one would also like a greater disaggregation of say, aid grants and loans each divided into budget support and project aid. In the absence of such information we propose three alternative versions of the model outlined above and leave it to statistical criteria to differentiate between them. The general forms of utility functions corresponding to each version are given below in Table 1. These models differ from those used in most previous studies through the assumption of asymmetric preferences, use of expenditure appropriation and revenue estimate data, in the use of alternative aid disaggregations and in their treatment of non-aid borrowing. $I_{g}$ represents investment or developmental expenditures, ${ }^{21} G_{h}$ denotes human capital related expenditures, consisting of expenditures in the health and education departments; $G_{o}$ is all other recurrent expenditures, defined as expenditures of all other departments and on special appropriations such as the retirement of debt; $T$ is taxation and other recurrent revenues, $A_{g}, A_{l}, A_{A}, A_{o}, A_{b}, A_{p}$ are aid grants, aid loans, Australian aid, aid from other sources, aid provided as budget support and project aid, respectively, and; $B$ is (non-aid) borrowing. 


\begin{aligned} \hline Model Version & Utility Function \\ \hline 1 & $=f\left(\sum_{j=1}^{k} E_{j} ; \sum_{m=1}^{n} R_{m}\right)=f\left(I_{g}, G_{h}, G_{o} ; T, A_{l}, A_{g}, B\right) \\ 2 & =f\left(\sum_{j=1}^{k} E_{j} ; \sum_{m=1}^{n} R_{m}\right)=f\left(I_{g}, G_{h}, G_{o} ; T, A_{A}, A_{o}, B\right) \\ 3 & =f\left(\sum_{j=1}^{k} E_{j} ; \sum_{m=1}^{n} R_{m}\right)=f\left(I_{g}, G_{h}, G_{o} ; T, A_{b}, A_{p}, B\right)\end{aligned}$

\section{Estimation Procedure and Results}

Structural equations for all model versions were estimated using data from GPNG (1962-2000). All data are in Kina, the PNG currency, expressed in constant (1995) prices and as a ratio to GDP. Disaggregated aid data are only available from 1969. This dictated using annual time-series data for the period 1969 to 2000 for all estimation. Estimates of the structural equation parameters were simultaneously obtained using the non-linear three-stage least squares (3SLS) method. This method is appropriate given that the system is simultaneous and that it contains cross-equation restrictions with respect to the $\rho$ and $\Phi$ parameters. The computer program used was TSP 4.5. Estimation of the reduced form equation parameters were obtained via simulations of the estimated structural equations. The statistic used to differentiate between model variants was their respective sum of squares residuals. Very careful consideration was given to structural instability. Given PNG's political environment, which has since the early 1990s become rather unstable, one might expect to find structural breaks in the data. Simple plots of each series and of the residuals of all equations were examined to detect structural breaks.

In the estimation of the models, coefficients were constrained to be consistent with the theoretical model. This has been a largely neglected area of the fiscal response literature and warrants some discussion. From constraint equation (3) it is apparent that the coefficients $\rho_{m}$ represent the proportions of their corresponding revenue variable allocated to recurrent expenditure. These coefficients should therefore have a value of between zero and one. Interpretations of a coefficient out of this range do not make sense. It is not possible to have a negative proportion allocated to an expenditure item, or a proportion exceeding 100 per cent. An examination of the utility function, expressed as the quadratic loss function outlined in (4) indicates that the $\beta \mathrm{s}$ and $\gamma_{\mathrm{s}}$ must be positive. If this is not the case, deviations from targets would yield more utility rather then less. It has also been shown that the $\rho$ s must have values 
between zero and one. Therefore, since the structural equation parameters are combinations of the $\beta s, \gamma$ s and $\rho$ s they must always be greater than or equal to zero (McGillivray and Ouattara, 2005). As McGillivray and Ouattara point out, an examination of the parameters in most previous fiscal response studies reveals inconsistencies between the theoretical models and the empirical results. As this issue is clearly also relevant to the current study, these parameters were restricted to within their theoretical range in the estimation of the structural equations. ${ }^{22}$

Estimating the structural parameters of the fiscal response models were obtained with no computational problems, with convergence being quickly obtained. Good structural equation functional fits were achieved. In most cases $R^{2} \mathrm{~s}$ were above 0.80 and ranged from 0.66 to 0.95 . Close inspection of each structural equation's residuals revealed, however, that corrective action for structural instability was not required. The version of the fiscal model yielding the lowest sum of squared residuals was Model 2, in which aid is disaggregated into Australian and other aid, respectively. While 2 is the preferred or true version there was no clearly superior version in this respect. We therefore rely on the results of all model versions, highlighting synergies between them rather than discrepancies.

Estimates of the structural equation parameters are shown in Table 2. Each structural equation contains 14 parameters. All of these parameters, except $\Phi_{3}, \Phi_{4}, \Phi_{6}$ in versions 1 and 3 of the model and $\Phi_{3}$ through to $\Phi_{6}$ in Version 2, are significantly different from zero at the 95 percent confidence level. The structural parameters of most interest are those of the constraint parameters that show how aid and other revenues have been allocated among the expenditure and revenue aggregates. $\rho_{2}$ shows either the proportion of aid grants, Australian aid or budget support allocated to consumption expenditure. $\rho_{3}$ shows either the share of aid loans, aid from other sources or project aid allocated to that expenditure. $\rho_{2}$ and $\rho_{3}$ range from 0.57 for project aid to 0.90 for aid loans, indicating that the majority of all categories of PNG aid inflows under consideration has been allocated to consumption expenditure and not to investment. Most of the $\rho$ s attached to aid variables are greater than 0.80 and only one is less than 0.70 . 
Table 2: Econometric Estimates of Structural Equation Parameters

\begin{tabular}{llllllc}
\hline & \multicolumn{5}{c}{ Model Version } \\
\cline { 2 - 7 } Parameter & \multicolumn{2}{c}{1} & \multicolumn{2}{c}{3} \\
\cline { 2 - 7 } & Estimate & $t$-statistic & Estimate & $t$-statistic & Estimate & $t$-statistic \\
\hline$\rho_{1}$ & $0.79^{*}$ & 18.51 & $0.81^{*}$ & 25.25 & $0.92^{*}$ & 14.13 \\
$\rho_{2}$ & $0.75^{*}$ & 13.71 & $0.72^{*}$ & 12.69 & $0.70^{*}$ & 11.8 \\
$\rho_{3}$ & $0.90^{*}$ & 15.28 & $0.86^{*}$ & 15.38 & $0.57^{*}$ & 2.09 \\
$\rho_{4}$ & $0.87^{*}$ & 18.27 & $0.88^{*}$ & 20.07 & $0.85^{*}$ & 14.41 \\
$\Phi_{1}$ & $0.48^{*}$ & 5.45 & $0.46^{*}$ & 5.78 & $0.38^{*}$ & 5.8 \\
$\Phi_{2}$ & $0.48^{*}$ & 6.1 & $0.56^{*}$ & 7.59 & $0.61^{*}$ & 9.56 \\
$\Phi_{3}$ & 0.45 & 0.88 & 0.49 & 0.96 & 0.31 & 0.68 \\
$\Phi_{4}$ & 0.09 & 0.29 & 0.06 & 0.26 & 0 & 0.05 \\
$\Phi_{5}$ & $0.66^{*}$ & 3.73 & 0.23 & 0.85 & $0.37^{*}$ & 2.53 \\
$\Phi_{6}$ & 0.08 & 0.86 & 0.13 & 1.36 & 0.04 & 1.13 \\
$\Phi_{7}$ & $0.41^{*}$ & 2.89 & $0.46^{*}$ & 3.03 & $0.51^{*}$ & 3.11 \\
$\Phi_{8}$ & $0.32^{*}$ & 4.12 & $0.35^{*}$ & 3.79 & $0.34^{*}$ & 3.08 \\
$\Phi_{9}$ & $0.60^{*}$ & 6.08 & $0.55^{*}$ & 5.03 & $0.63^{*}$ & 4.49 \\
$\Phi_{10}$ & $0.38^{*}$ & 4.27 & $0.41^{*}$ & 4.28 & $0.40^{*}$ & 3.77 \\
\hline
\end{tabular}

* indicates significantly different from zero at the 95 per cent confidence level 
The estimates of $\rho_{2}$ and $\rho_{3}$ provide a number of messages about the fungibility of aid to PNG. It is understandable and appropriate that donors will want to support consumption expenditure, especially that which has a pro-human capital orientation. But aid has traditionally had a sustained growth via fixed capital accumulation orientation to it. It is unlikely, therefore, that they would want the majority of aid to fund these expenditures. It is unlikely in the extreme that they would want only 25 percent or less of their aid to be allocated to fixed capital investment, as is the case with most of the categories of aid under consideration. While fiscal response models do not reveal the full extent of fungibility, it would appear that aid to PNG has in general been highly fungible. ${ }^{23}$ While one needs to acknowledge that expenditure on health and education can be good for growth, the implied extent of fungibility adds weight to concerns over the capacity or willingness of the PNG public sector to use aid in ways deemed appropriate for sustained economic growth. This is not to say that aid has not been pro-growth in PNG, but it might imply that its contribution to growth is less than would have otherwise been the case. ${ }^{24}$

That loans appear to be the most fungible aid category and project aid the least deserves some comment. Loans are generally thought to be highly pro-fixed investment; both donor and recipient countries want them to effectively augment future income levels given that they need to repaid. That 90 percent of aid loans to PNG are allocated to consumption is clearly out of step with this common perception. Why might this be so? Aid recipients will often approach donors for additional support if there is an unanticipated deficit in the recurrent budget. PNG has been known to do this. ${ }^{25}$ Donors have been known to provide this support in the form of a loan rather than a grant. This could partly explain why such a high proportion of aid loans to PNG has seemingly been allocated to consumption. ${ }^{26}$ It is also worth noting that the alternative estimates of $\rho_{4}$ suggest that between 85 and 88 percent of non-aid borrowing $(B)$ has been allocated to consumption expenditure. Presumably this, has primarily been to cover an anticipated deficit in the recurrent budget. The estimates of $\rho_{1}$ indicate that between 79 and 92 percent of tax and other recurrent revenue has been allocation to the consumption. There public sector in PNG saves little, it therefore seems. The three previous studies of the fiscal response to aid in failing (or predominantly failing) states (McGillivray and Ouattara, 2005, Mavrotas and Ouattara, 2006 and Feeny, 2007) report broadly consistent results to those just reported for PNG. In particular, they each find that borrowing is mainly allocated to recurrent expenditure and that most aid tends to be allocated to consumption. ${ }^{27}$

Budget support aid to PNG was gradually phased out during the 1990s in favour of project aid. The comparatively low proportion of project aid that has been allocated to consumption is consistent with the manner in which this form of aid is typically provided. That is, donors are much more closely involved in the disbursement of project aid funds and can ensure they get spent in a way that they intended. Fungibility is, though, more complex than this. Recipients can simply allocate less of their own funds to a particular expenditure program in response to donors supporting it. Aid funds are therefore used to displace rather than 
augment domestic expenditure, contrary to donor intentions. This would appear to be behind the apparent extent of fungibility of project aid to PNG.

Some comments on constraint equation parameter estimates reported by previous studies are also warranted. It is common for these parameters to be above 0.70 and in some cases close or equal to unity. ${ }^{28}$ The parameter attached to tax and other recurrent revenue is within the range of 0.70 to just under 0.90 , while that attached to non-aid borrowing can be as high as unity. McGillivray and Ouattara (2005) report the latter result for Cotê d'Ivoire and Feeny (2007) for a sample mainly comprised of failing states in Melanesia. But what sets PNG apart from other countries examined in the fiscal response literature is that its constraint equation parameters are consistently high: it is rare by international standards to observe $\rho s$ that are so consistently highly for all revenue variables under consideration. This is another possible signal that aid might not have been as effective as could otherwise have been the case.

The constraint equations might reveal important and interesting information, but they only tell part of the story told by fiscal response models regarding the impact of aid on public sector fiscal aggregates. A more complete story of the direct incremental impacts of aid is told by mechanisms embodied within the system of structural equations. Yet these impacts are by definition partial, with the full story involving direct and indirect incremental impacts being told by the reduced form parameter estimates. The direct incremental effects of the aid variables are shown in Table 3. The most consistent direct effects are that all categories of aid lead to reductions in taxation and borrowing and increases in other (non human capital oriented) consumption. The first of these results is potentially worrying, in that it indicates that aid reduces taxation effort. The magnitude of this effect is especially worrying, as it seems that a one Kina increase in aid results in a 0.93 kina reduction in taxation revenue. McGillivray and Ouattara (2005), Mavrotas and Ouattara (2006) and Feeny (2007) each report broadly similar results.

Reduced form parameters are shown in Table 4. Only those relating to the impact of the aid variables are reported. ${ }^{29}$ The aid variables under consideration are the PNG government's estimates of the amount of aid funds available for disbursement in the current year. These estimates are, however, based on the amounts of funds donors decide to allocate to PNG. It is well accepted in the literature that these amounts are in general primarily supply-side determined, based on a range of criteria donors employ in determining aid allocations to recipient countries. This also applies to PNG, which has little influence over the amounts of aid funds made available to it by donors. ${ }^{30}$ The reduced form parameters attached to the aid variables, therefore, show the impacts of donor decisions regarding the amounts of aid to provide to PNG. 
Table 3: Direct Incremental Impact of Aid Variables

\begin{tabular}{lcccc}
\hline & & \multicolumn{3}{c}{ Estimate from Model Version } \\
\cline { 3 - 5 } Impact & Mechanism & 1 & 2 & 3 \\
\hline & & $\mathrm{A}_{\mathrm{g}}$ & $\mathrm{A}_{\mathrm{A}}$ & $\mathrm{A}_{\mathrm{b}}$ \\
$A_{g}, A_{A}$ or $A_{b}$ on $I_{g}$ & $\left(1-\rho_{2}\right)-\left(1-\rho_{1}\right)\left(\rho_{2} \Phi_{2}+\Phi_{1}\right)$ & 0.08 & 0.11 & 0.24 \\
$A_{g}, A_{A}$ or $A_{b}$ on $G_{h}$ & $\rho_{2}-\rho_{1}\left(\Phi_{1}+\rho_{2} \Phi_{2}\right)$ & 0.08 & 0.03 & -0.04 \\
$A_{g}, A_{A}$ or $A_{b}$ on $G_{o}$ & $\rho_{2}-\rho_{1}\left(\Phi_{3}+\rho_{2} \Phi_{4}\right)$ & 0.33 & 0.29 & 0.41 \\
$A_{g}, A_{A}$ or $A_{b}$ on $T$ & $-\left(\rho_{2} \Phi_{2}+\Phi_{1}\right)$ & -0.84 & -0.86 & -0.8 \\
$A_{g}, A_{A}$ or $A_{b}$ on $A_{l}$ & $-\left(\rho_{2} \Phi_{8}+\Phi_{7}\right)$ & -0.65 & -0.71 & -0.75 \\
$A_{g}, A_{A}$ or $A_{b}$ on $B$ & $-\left(\rho_{2} \Phi_{10}+\Phi_{9}\right)$ & -0.88 & -0.85 & -0.91 \\
$A_{l}, A_{o}$ or $A_{p}$ on $I_{g}$ & $\left(1-\rho_{3}\right)-\left(1-\rho_{1}\right)\left(\rho_{3} \Phi_{2}+\Phi_{1}\right)$ & -0.09 & -0.04 & $\mathrm{~A}_{\mathrm{p}}$ \\
$A_{l}, A_{o}$ or $A_{p}$ on $G_{h}$ & $\rho_{3}-\rho_{1}\left(\Phi_{1}+\rho_{3} \Phi_{2}\right)$ & 0.17 & 0.1 & -0.37 \\
$A_{l}, A_{o}$ or $A_{p}$ on $G_{o}$ & $\rho_{3}-\rho_{1}\left(\Phi_{3}+\rho_{3} \Phi_{4}\right)$ & 0.48 & 0.42 & 0.28 \\
$A_{l}, A_{o}$ or $A_{p}$ on $T$ & $-\left(\rho_{3} \Phi_{2}+\Phi_{1}\right)$ & -0.92 & -0.94 & -0.73 \\
$A_{l}, A_{o}$ or $A_{p}$ on $A_{g}$ & $-\left(\rho_{3} \Phi_{6}+\Phi_{5}\right)$ & -0.73 & -0.34 & -0.4 \\
$A_{l}, A_{o}$ or $A_{p}$ on $B$ & $-\left(\rho_{3} \Phi_{10}+\Phi_{9}\right)$ & -0.94 & -0.88 & -0.86 \\
\hline
\end{tabular}


Table 4: Reduced Form Equation Parameter Estimates

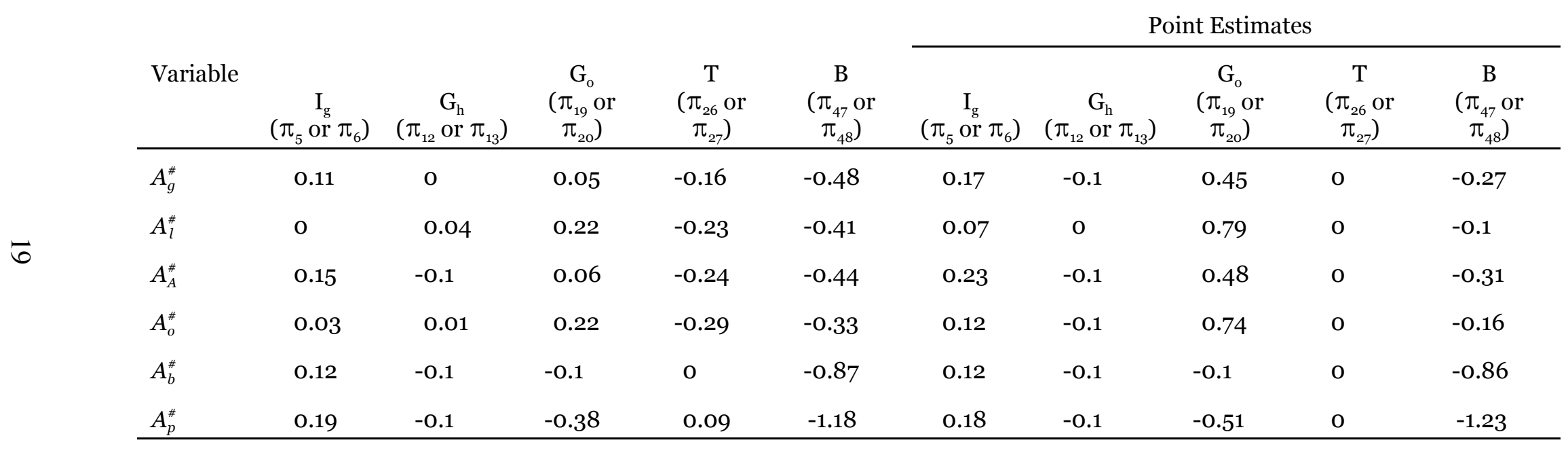


Two sets of reduced form parameter estimates are reported. The first has been obtained by substituting relevant estimated values of the $\Phi_{\mathrm{s}}$ and $\rho$ s into the corresponding $\pi$ parameter. Structural parameters judged not to be significantly different from zero on the basis of $t$-tests were given a value of zero in this process. The second set of estimates shown in Table 4 are standard point estimates, in which all structural equations were used to calculate $\pi$ values, irrespective of their corresponding $t$-statistics. We rely primarily on the first set of estimates.

Two consistent results emerge from the estimates reported in Table 4.The first is that all categories of aid lead to reductions in borrowing, based on the estimates of $\pi_{47}$ and $\pi_{48}$. Project aid has the largest impact, with each additional kina of these inflows leading to a roughly 1.2 kina reduction in borrowing. In the final analysis, therefore, it seems that the PNG public sector treats aid inflows as a substitute for borrowing. This outcome sets PNG aside from other countries examined in the fiscal response and related literatures. A common finding in these literatures is that aid is positively associated with borrowing (Feeny and McGillivray, 2003). McGillivray and Morrissey (2001b) attribute this to 'aid illusion', where a given amount of aid results in an unintentionally larger amount of expenditure, causing recipients to borrow in order to cover the gap. Any upward pressure on borrowing is driven by factors other than aid, it would therefore appear.

The second consistent result is that, based on the estimates of $\pi_{5}$ and $\pi_{6}$, all categories of aid are positively associated with public fixed investment expenditure. Each additional kina of aid leads to an increase in this expenditure of between 0.03 and 0.23 kina, depending on the category of aid under consideration. The only possible exception is aid loans, as the non-point estimate of $\pi_{6}$ obtained when this variable is used is zero. The result for investment can reasonably be seen as a good thing, given its implications for growth. One though is left to speculate as to what this outcome might have been had a greater share of aid been allocated to investment.

The remaining reduced form parameter estimates provide less consistent information on aid and public sector fiscal aggregates in PNG. However, most non-point estimates of the coefficients of aid on taxation $\left(\pi_{26}\right.$ and $\pi_{27}$ ) are negative, suggesting that aid has resulted in lower tax revenues than would have otherwise been the case. There is evidence, therefore, that aid has been used as a substitute for taxation. This does not send a good signal for the effectiveness to PNG, being indicative of aid dependence. This is a common finding in the fiscal response literature, with many other recipient countries using aid in this way (McGillivray and Morrissey, 2001a).The evidence of links between aid and consumption expenditure is rather mixed, based on estimates of $\pi_{12}, \pi_{13}, \pi_{19}$ and $\pi_{20}$. There are no clear signals regarding the impact of aid on consumption expenditure of a human capital orientation. Perhaps all that can be said about this impact is that it is very negligible. Most categories of aid and other consumption expenditure are positively related. The relevant parameters are larger in 
magnitude than those between aid and fixed investment, suggesting that aid has had a greater consumption than investment orientation in PNG.

\section{Conclusion}

Aid flows are an important component of the public sector budgets of most developing countries. A greater understanding of the interactions between aid and various categories of public sector expenditure and revenue is required if aid is to contribute further to economic growth and the achievement of the internationally agreed MDGs. This paper has sought to contribute to this understanding in two ways. The first was to further improve the aid-fiscal behaviour literature by addressing two key, widely acknowledged weaknesses in fiscal response models. This involved building a model that allows for asymmetric fiscal decision maker preferences and uses expenditure appropriations and revenue estimates rather than vaguely defined and statistically generated targets. The second contribution was to apply this model to Papua New Guinea (PNG), using 1969 to 2000 annual time-series data. As outlined above, PNG is a particularly interesting case study. It is a country that has experienced many economic, political and social difficulties, despite receiving relatively large amounts of aid. It has recently been classified as a fragile state by the international donor community, in part based on perceptions that it has a weak and ineffective public sector. It is also a country that is generally considered to have not used aid especially effectively, and the Australian government (the largest donor of aid to PNG) has responded to this and the general state of affairs in PNG in a rather radical manner by placing its own civil servants in key positions in the PNG's public sector.

The results obtained from applying the fiscal response model to PNG paint a picture of a poorly performing public sector that has not used aid and other revenues especially well and worse than many other countries examined in the literature. Consistently high proportions of taxes and other recurrent revenue, aid and non-aid borrowing are allocated to consumption expenditure and there is evidence of aid loans financing unanticipated shortfalls in the recurrent budget and of aid displacing other recurrent revenue. There were some pleasing results, with aid being positively associated with fixed investment and non-aid borrowing but the overall picture of the effectiveness of aid to PNG is relatively poor. This is not at all to say that aid has failed PNG, in that it has failed to contribute to growth and by assumption poverty reduction. Indeed, there is evidence from the aid-growth literature that growth in PNG would be lower in the absence of aid. But it does suggest that the manner in which the PNG public sector has used aid has limited the overall effectiveness of these inflows in promoting growth and more importantly reducing poverty. To these extents there would appear to be empirical support for the radical Australian intervention mentioned at the outset of this paper. Time will, of course, be the ultimate judge as to its success.

Finally, some comments on the impact of aid on public sector fiscal aggregates in failing states in general and for donor policy are warranted. Here we rely not only on the results 
reported in this study, but also on the findings from other studies examining aid and the public sector in failing states, cited above. These comments relate to failing states that are similar to PNG in this regard, and not to those without any functioning public sector. Clearly, the results reported in this paper and the other studies will not be relevant to such states. These results suggest that failing states are characterised by using non-aid borrowing to fund recurrent budgets. Findings also suggest that these states use aid as a substitute for taxation and other recurrent revenue: these revenues decrease in response to aid inflows. Donors need to be conscious of both outcomes in the design and delivery of aid programs to failing states. The former we interpret as the result of unexpected shortfalls in revenues. Such behaviour could be justified as a response to a revenue decline if it means that essential expenditures such as the delivery of key services is maintained. However, in the longer term, this justification would appear to be difficult to support. Public sector borrowing needs to be repaid, increasing the level of debt and a country's future debt service obligations. Given the political instability and future uncertainty often associated with failing states, politicians currently holding office might be more disposed to undertaking such borrowing.

The preceding finding also highlights the need to accurately forecast revenue estimates. Overly optimistic estimates of expected revenue will exacerbate the problem of public sectors not being able to meet their expenditure appropriations. Donors could assist in strengthening the ability of public sectors to undertake this exercise effectively. Further donors must be sympathetic to the financial requirements of public sectors which have experienced external shocks. Natural disasters and unexpected falls in the prices of key commodities can derail good public sector financial management. Donors should ensure their own aid flows are predictable and could supplement other unexpected revenue shortfalls to prevent higher levels of commercial borrowing.

The finding that taxation and other recurrent revenues fall in response to aid inflows in failing states is a potentially serious matter for international aid donors. Trade liberalisation conditions, sometimes attached to the receipt of foreign aid could, at least partially, explain this finding. However, the finding is also likely to reflect recipients developing a long-run dependence on aid inflows as a revenue source. Failing states often have low revenue bases and sometimes a weak commitment or limited ability to collect taxes. To mitigate this impact of foreign aid it is important for international donors to work with recipient public sectors in strengthening revenue collection and management. 


\section{Notes}

1. See, for example, DFID (2005), McGillivray (2005) and ODI (2004).

2. As will be evident from the discussion that follows in this paper, the term 'fragile state', as used in the donor community, is rather misleading, to the extent that it is not used to delineate states only in terms of their likelihood of breaking-up or vulnerability to downside shocks. It is for this reason that the term 'failing' state is subsequently used in this paper. It is these states that is the focus of Paul Collier's comprehensive and engaging recent book (Collier, 2007). Note that Collier also primarily relies on the term failing as opposed to fragile.

3. These countries were classified as fragile based on them being in the World Bank Lowincome Country Under Stress (LICUS) group. The other classification criterion deems a country as fragile if it belongs to the bottom two quintiles of the CPIA (defined below) or were not rated as part of the CPIA exercise. 35 countries were deemed fragile according to this criterion in 2004 (McGillivray, 2005).

4. The two alternative criteria for assigning a country to the fragile state group are: (i) if it falls into the World Bank low-income country group and has a World Bank Country Performance and Institutional Assessment (CPIA) score of 3.0 or less and; (ii) it belongs to the bottom two CPIA quintiles or was not assessed in the current CPIA round. Note that the first criterion is also used by the World Bank to assign a country to the Lowincome Country Under Stress (LICUS) group (McGillivray, 2005). The statistics just quoted are for the LICUS group.

5. It is also fully consistent with the findings of the very seminal and influential Burnside and Dollar (2000) study, which found that the impact of aid on per capita GDP growth is contingent on the quality of recipient country policies. It also assists in providing an explanation as to why Rajan and Subramanian (2008) fail to find any systematic impact of aid on growth.

6. The important contribution of Mosley et al. (1987) should not be overlooked. This innovative study used the Heller model as a basis for analysing links between aid and growth using cross-country data.

7. There is also a related literature, primarily concerned with the fungibility of aid. Fungibility occurs when a recipient is able to use aid funds for a purpose different to that intended by the donor. As such these studies look at the determinants of expenditure, treating revenues as exogenous and not looking at the interaction between revenues and expenditures. Better known studies of this kind include Cashell-Cordo and Craig (1990), Pack and Pack (1990, 1993), Khilji and Zampelli (1991, 1994), Feyzioglu et al. (1998) and Swaroop et al. (2000). 
8. Feeny (2007) is an exception, although little elaboration of the approach taken, in particular its advantages, is provided.

9. Feeny (2007) predominantly looked at failing states, to the extent that the study examined aid and fiscal aggregates using panel data for five countries, of which four are classified as failing. Those countries were Papua New Guinea, the Solomon Islands, and Vanuatu. The remaining country was Fiji.

10. Franco-Rodriguez et al. (1998) proposed specific forms of (2) and (3) following criticisms of previous constraints used in the fiscal response literature from White (1994). White criticised the inclusion of the $\rho$ s in these constraints on the grounds that they over constrained the utility maximisation problem, necessarily preventing (1) from reaching its maximum even if actual revenues were such that expenditure targets could be met. The Franco-Rodriguez et al. response is that this is what should happen given the realities of fiscal policy in developing countries.

11. For a model containing only one expenditure variable and one revenue variable, the linear quadratic function is:

$$
U=\alpha+\sum_{j=1}^{k}\left[\beta_{j, 1}\left(E_{j}-E_{j}^{*}\right)-\frac{\beta_{j, 2}}{2}\left(E_{j}-E_{j}^{*}\right)^{2}\right]-\sum_{m=1}^{n}\left[\gamma_{m, 1}\left(R_{m}-R_{m}^{*}\right)-\frac{\gamma_{m, 2}}{2}\left(R_{m}-R_{m}^{*}\right)^{2}\right]
$$

12. Binh and McGillivray (1993) further demonstrate that (1) satisfies both attributes, although they do note that its symmetry would appear to be restrictive. As almost all subsequent fiscal response studies since Binh and McGillivray (1993) have used a quadratic loss function without linear terms, it seems that they implicitly accept that the loss of asymmetric preferences is a price worth paying for satisfying the two attributes.

13. Heller (1975) and Khan and Hoshino (1992) are exceptions to this general rule. They substitute un-estimated target variable equations into their structural equations, prior to the estimation of the latter. As McGillivray and Morrissey (2001a) observe, this essentially treats the target variable equations as identities. Such an approach would appear to be problematic given the variables appearing on the left hand side of the target equations, which are not suited to identities, and that it increases substantially the number of parameters to be estimated.

14. The exception is the aid target in fiscal response studies that follow Franco-Rodriguez et al. (1998). This variable is defined as aid committed by donors for disbursement by the recipient. A case for its exogeneity is provided (which is based on informational time lags, imperfect expectations and bureaucratic rigidity), and actual data on commitments are available. 
15. The exception is White (1994), who identified two further problems with estimating the targets in the manner just outlined. The first problem is that the target variable estimates will almost certainly be inconsistent with the overall constraint written in (2) above, given that they have been obtained independently of each other. The second problem, related to that just discussed, arises if one obtains a high functional fit from the equations used to estimate the targets. This will mean that a large amount of the variation in the dependent variable of the relevant structural equation will be explained by the parameter on its target variable, leaving a very small amount of residual variation to be picked up by the parameters on the other explanatory variables. Consequently, the target variable parameter will be highly significant statistically, with a value close to one, while those attached to the other variables will almost certainly be insignificant irrespective of how important these variables might actually be.

16. It is not uncommon for appropriations and estimates to be formulated many years in advance, consistent with a medium-term policy stance. These aggregates are though invariably updated on an annual basis. The key point, for our current purposes, that they are determined in the year or years prior to $t$.

17. Our belief that the second above-mentioned scenarios is appropriate to PNG is based on qualitative evidence obtained from the fieldwork on which research for this paper is partially based. Various interviews were conducted with aid officials in PNG and those connected with the PNG Treasury.

18. It can be easily shown that the second order derivatives are always negative. See Feeny (2006) for further details. Feeny argues that selecting either a form consistent with (1) or a function consistent with (4) is unlikely to make much difference empirically, in that both result in similar structural equations if a common set of variables is employed. The primarily justification for using a variant of (4) is conceptual, therefore.

19. Taylor's approximation works best for small values of $x$. In subsequent empirical analysis all data are expressed as a ratio of GDP.

20. They are available on request from the authors.

21. Note that the PNG Budget changed its classification in 1994. From this year, capital expenditures were incorporated into a wider development budget which included other development related expenditures. Although a strict definition of the development budget does not exist, donors funding any of the activities involved in the development budget will be desirable since it promotes long term development by definition. A structural break was included in the estimation of the empirical model to capture the budget reclassification but results remained unchanged.

22. Tests for unit roots were not conducted, as this issue remains unexplored in the context of non-linear systems estimation. There is no known technique for addressing this issue 
in this context. Nor is there evidence to suggest that using an estimator like non-linear three stages least squares produces biased results if the data are non-stationary.

23. As McGillivray and Morrissey (2001b) observe, the $\rho$ s in fiscal response models only reveal the precise extent of fungibility if ones knows what proportion of aid donors intended to be allocated to either consumption or investment.

24. Feeny (2005) shows evidence that growth in PNG would be lower in the absence of aid flows.

25. This assertion is based on press reports over recent years and field interviews with those involved in the PNG aid program.

26. Interviews with officers involved in the aid program revealed that this has happened with Australian assistance to PNG. It might also have been the case that donors wanted to support recurrent expenditure of a human capital orientation with loans, but this is unlikely. Grants would instead be used for that purpose.

27. Feeny (2007) finds that although most grant aid is allocated to a development budget in Melanesian countries, the majority of aid loans are allocated to recurrent expenditures.

28. Here we refer to the fiscal studies cited above that report plausible values of the $\rho$, in particular ignoring those reporting values outside of the range of zero and one.

29. Estimates of the remaining reduced form parameters are available on request from the authors.

30. It does influence the amount of aid that is actual spent, and it is for this reason that actual as opposed to estimated aid is treated as endogenous. 


\section{References}

Australian Agency for International Development (AusAID). Australia-Papua New Guinea Enhanced Co-operation Program, AusAID, Canberra, 2004.

Binh, T.N. and M. McGillivray. Foreign aid, taxes and public investment: A comment, Journal of Development Economics 1993; 41; 173-176.

Branchflower, A., S. Hennell, S. Pongracz and M. Smart. How Important Are Difficult Environments to Achieving the MDGs?, PRDE Working Paper 2, Poverty Reduction in Difficult Environments Team, Policy Division, UK Department for International Development, London, 2004.

Burnside, C. and D. Dollar. Aid, policies and growth, American Economic Review 2000; 90; 847-868.

Cashel-Cordo, P. and S. Craig. The public sector impact of international resource transfers, Journal of Development Economics 1990; 32; 17-42.

Chishti, S. and M. Hasan. Foreign aid, defence expenditure and public investment in Pakistan, Pakistan Development Review 1992; 31; 895-908.

Collier, P. The Bottom Billion: Why the Poorest Countries are Failing and What Can Be Done About It, Oxford University Press, Oxford, 2007.

Department for International Development (DFID). Why we need to work more effectively in fragile states, DFID, London, 2005.

Feeny, S. The impact of foreign aid on economic growth in Papua New Guinea, Journal of Development Studies 2005; 41; 1092-1117.

Feeny, S. Policy preferences in fiscal response studies, Journal of International Development $2006 ; 18 ; 1167-1175$.

Feeny, S. Foreign assistance and fiscal governance in Melanesia, World Development 2007; 35; 439-53.

Feeny, S. and M. McGillivray. Aid and public sector borrowing in developing countries, Journal of International Development 2003; 15; 989-998.

Feyzioglu, T., V. Swaroop and M. Zhu. A panel data analysis of the fungibility of foreign aid, World Bank Economic Review 1998; 12; 29-58.

Franco-Rodriguez, S., M. McGillivray, M. and O. Morrissey. Aid and the public sector in Pakistan: Evidence with endogenous aid, World Development 1998; 26; 1241-1250.

Franco-Rodriguez, S. Recent advances in fiscal response models with an application to Costa Rica, Journal of International Development 2000; 12; 429-442.

Gang, I.N. and H.A. Khan. Foreign aid, taxes and public investment, Journal of Development 
Economics 1991; 24; 355-369.

Gang, I.N. and H.A. Khan. Reply to Tran-Nam Binh and Mark McGillivray: Aid, taxes and public investment: A comment, Journal of Development Economics 1993; 41; 177-178.

Gang, I.N. and H.A. Khan. Foreign aid and fiscal behaviour in a bounded rationality model: Different policy regimes, Empirical Economics 1999; 24, 121-134.

Government of Papua New Guinea (GPNG). Budget Papers: Estimates of Revenues and Expenditures, Department of Treasury, Port Moresby, 1962-2002.

Heller, P.S. A model of public fiscal behaviour in developing countries: Aid, investment and taxation, American Economic Review 1975; 65; 429-445.

Hughes, H. Aid has failed the Pacific, Issue Analysis No. 33, Sydney, Centre for Independent Studies, 2003.

Jones, S., R. Riddell and K. Kotonglou. Aid allocation: Managing for development results and difficult partnerships, Summary paper prepared for the DAC Learning and Advisory Process on Difficult Partnerships, Oxford Policy Management, Oxford, 2004.

Khan, H.A. and E. Hoshino. Impact of foreign aid on the fiscal behaviour of LDC governments, World Development 1992; 20; 1481-1488.

Khan, H.A. The impact of foreign aid on the fiscal behaviour of Asian LDC governments: Reply to Mark McGillivray, World Development 1994; 22; 2019-2020.

Khilji, N. and E. Zampelli. The fungibility of US assistance to developing countries and the impacts on recipient expenditures: A case study of Pakistan, World Development 1991; 19; 1095-106.

Khilji, N. and E. Zampelli. The fungibility of US military and non-military assistance and the impacts on expenditures of major aid recipients, Journal of Development Economics $1994 ; 43 ; 345-362$.

Mavrotas, G. Foreign aid and fiscal response: Does aid disaggregation matter?, Weltwirtschaftliches Archiv 2002; 138; 534-59.

Mavrotas, G. Aid Heterogeneity: Looking at aid effectiveness from a different angle, Journal of International Development 2005; 17; 1019-1036.

Mavrotas, G and B. Ouattara. Aid disaggregation and the public sector in aid-recipient economies: Some evidence from Côte d'Ivoire, Review of Development Economics 2006; 10; 434-451.

McGillivray, M. and A. Ahmed. Aid, adjustment and public sector fiscal behaviour in the Phillippines, Journal of the Asia Pacific Economy 1999; 4; 381-91.

McGillivray, M. and O. Morrissey. Fiscal effects of aid, Discussion Paper No. 2001/61, World 
Institute for Development Economics Research, Helsinki, 2001a.

McGillivray, M. and O. Morrissey. Aid illusion and public sector fiscal behaviour, Journal of Development Studies 2001b; 37; 118-136.

McGillivray, M. and B. Ouattara. Aid, debt burden and government fiscal behaviour in Cotê d'Ivoire, Journal of African Economies 2005; 14; 247-269.

McGillivray, M. The impact of foreign aid on the fiscal behaviour of Asian LDC governments: A comment on Khan and Hoshino, World Development 1994; 22; 2015-2017.

McGillivray, M. Aid and public sector fiscal behaviour in developing countries, Review of Development Economics 2000; 4; 156-163.

McGillivray, M. Aid allocation and fragile states. Background paper prepared for the Senior Level Forum on Development Effectiveness in Fragile States, 13-14 January 2005, Lancaster House, London, 2005.

Mosley, P., J. Hudson, S. Horrel. Aid, the public sector and the market in less developed economies, Economic Journal 1987; 97; 616-641.

Overseas Development Institute (ODI). Aid to 'poorly performing' countries: a critical review of debates and issues, ODI, London, 2004.

OECD. International Development Statistics, On-line Database. OECD, Paris, 2005.

OECD. DACNews: ideas on aid, Paris, OECD, April, 2006

Otim, S. Foreign aid and government fiscal behaviour in low-income South Asian countries, Applied Economics 1996; 28; 927-933.

Ouattara, B. Foreign aid and government fiscal behaviour in developing countries: Panel data evidence, Economic Modelling 2006a; 23; 506-514.

Ouattara, B. Aid, debt and fiscal policies in Senegal, Journal of International Development 2006b; 18; 1105-1122.

Pack, H. and J.R. Pack. Is foreign aid fungible? The case of Indonesia, Economic Journal 1990; $100 ; 188-194$.

Pack, H. and J.R. Pack. Foreign aid and the question of fungibility, Review of Economics and Statistics 1993; 75; 258-265.

Pagan, A. Econometric issues in the analysis of regressions with generated regressors, International Economic Review 1984; 25; 393-415.

Rajan, R.G. and A. Subramanian. Aid and growth: what does the cross country evidence really show? The Review of Economics and Statistics 2008; 90:643-65.

Swaroop, V., S. Jha and A. Rajkumar. Fiscal effects of foreign aid in a federal system of 
governance: The case of India, Journal of Public Economics 2000; 77; 307-330.

UNDP. Human Development Report, Oxford University Press, New York, 1993-2003.

UN Millennium Project. Investing in development: A practical plan for achieving the Millennium Development Goals ( United Nations Development Program, New York), 2005.

White, H. The macroeconomic impact of development aid: A critical survey, Journal of Development Studies 1992; 28; 163-240.

White, H. Foreign aid, taxes and public investment: A further comment on Gang and Khan, Journal of Development Economics 1994; 45; 155-63.

Windybank, S and M. Manning. Papua New Guinea on the brink, Issue Analysis No.30, Sydney, Centre of Independent Studies, 2003.

Wooldridge, J. Econometric Analysis of Cross Section and Panel Data. The MIT Press, Cambridge MA, 2002.

World Bank. 2003 CPIA quintiles, World Bank, Washington, 2003. 